\title{
800 anos de ocupação da Tradição Polícroma da Amazônia: um panorama histórico no Baixo Rio Solimões
}

800 years of occupation of the Amazonian Polychrome Tradition: a historical overview in the Lower Solimoes River

\section{Eduardo Kazuo Tamanaha e Eduardo Góes Neves}

\section{(2) OpenEdition Journals}

\section{Edição electrónica}

URL: http://journals.openedition.org/aa/1255

DOI: 10.4000/aa. 1255

ISSN: 2357-738X

\section{Editora}

Programa de Pós-Graduação em Antropologia Social (UnB)

\section{Edição impressa}

Data de publição: 1 dezembro 2014

ISSN: 0102-4302

\section{Refêrencia eletrónica}

Eduardo Kazuo Tamanaha e Eduardo Góes Neves, «800 anos de ocupação da Tradição Polícroma da Amazônia: um panorama histórico no Baixo Rio Solimões», Anuário Antropológico [Online], v.39 n.2 I 2014, posto online no dia 01 agosto 2017, consultado o 28 abril 2021. URL: http:// journals.openedition.org/aa/1255 ; DOI: https://doi.org/10.4000/aa.1255

Este documento foi criado de forma automática no dia 28 abril 2021.

\section{c)}

Anuário Antropológico is licensed under a Creative Commons Atribuição-Uso Não-Comercial-Proibição de realização de Obras Derivadas 4.0 International. 


\title{
800 anos de ocupação da Tradição Polícroma da Amazônia: um panorama histórico no Baixo Rio Solimões
}

\author{
800 years of occupation of the Amazonian Polychrome Tradition: a historical \\ overview in the Lower Solimoes River
}

Eduardo Kazuo Tamanaha e Eduardo Góes Neves

\section{NOTA DO EDITOR}

Recebido em: 13 de julho de 2014

Aceito em: 01 de outubro de 2014

À Fundação de Amparo à Pesquisa do Estado de São Paulo (FAPESP), Petrobras e Instituto de Desenvolvimento Sustentável Mamirauá pelo financiamento das pesquisas de campo e laboratório; ao corpo docente e aos funcionários do Museu de Arqueologia e Etnologia da Universidade de São Paulo (MAE/USP), e a todos os colegas do PAC e do Laboratório de Arqueologia dos Trópicos (Arqueotrop), pela intensa convivência produtiva; e a todos aqueles que participaram dos sítios-escolas e das escavações dos sítios aqui apresentados.

\section{Introdução}

$1 \mathrm{Na}$ arqueologia do Baixo Rio Solimões, são visíveis na superfície dos sítios com solos antrópicos de terras pretas fragmentos de cerâmicas pintadas em vermelho, preto e branco. Tais cerâmicas pertencem à Fase Guarita (séculos VIII a XVI d.C.) da Tradição Polícroma da Amazônia, definida por Peter Paul Hilbert em sua obra de 1968 (Hilbert, 1968:152), e estão associadas às últimas ocupações pré-coloniais que antecedem a 
chegada do europeu na região. Devido à sua decoração pintada e plástica, cerâmicas Guarita chamaram a atenção de diversos pesquisadores desde o século XIX, como as pranchas desenhadas por Barbosa Rodrigues (1877) na apresentação de "A necrópole de Miracanguera", publicada no volume Arte cerâmica: antiguidades do Amazonas. Já no século XVI, o cronista Gaspar de Carvajal, durante a expedição de Francisco de Orellana, em 1542, relatava sobre uma aldeia, na região do atual município de Coari, por ele nomeada como Aldeia da Louça, que possuía uma cerâmica de "la mejor que se há visto en el mundo, porque la de Málaga no se iguala con ella, porque es toda vidrada y esmaltada de todos colores y tan vivas que espantan" (Papavero et al., 2002:31).

2 Sítios com cerâmicas da Tradição Polícroma têm uma ampla distribuição pela Amazônia e podem ser encontrados desde o Alto Rio Napo, no sopé dos Andes equatorianos, e o Baixo Rio Ucayali, no Peru, até a ilha de Marajó, na foz do Amazonas. Essa ampla distribuição tem sido objeto de estudo desde os anos 1950, por meio da apresentação de hipóteses difusionistas, com perspectivas históricas distintas (Brochado, 1989; Meggers \& Evans, 1957, 1961, 1968; Lathrap, 1975). Tais hipóteses não serão aqui revistas, mas é importante destacar como cerâmicas da Tradição Polícroma - principalmente as produzidas na Amazônia central e Amazônia ocidental - têm uma grande padronização formal e estilística que permite sua fácil identificação, mesmo que tenham sido produzidas em sítios localizados a milhares de quilômetros de distância (Meggers \& Evans, 1968; Boomert, 2004).

3 O objetivo deste artigo é verificar se à padronização estilística das cerâmicas Guarita corresponde também uma padronização tecnológica. Para isso, selecionamos sete sítios arqueológicos distribuídos ao longo de uma faixa de cerca de $400 \mathrm{~km}$ às margens do Rio Solimões e seus afluentes, desde a cidade de Coari, a oeste, até o encontro dos rios Solimões e Negro, próximo a Manaus, a leste (Tamanaha, 2012).

\section{Área pesquisada e trabalhos realizados}

4 A área pesquisada neste trabalho pode ser dividida em duas partes, tanto pelo seu posicionamento geográfico como pelo seu contexto arqueológico: o entorno da confluência entre os rios Solimões e Negro e a região do município de Coari. Tal divisão se faz necessária para entendermos os processos históricos de surgimento e expansão dos grupos portadores da cerâmica Guarita na área estudada. Foram selecionados sete sítios arqueológicos, sendo dois (Hatahara e Laguinho) localizados na área de confluência e os outros cinco (Santa Fé, Nova Esperança, São Paulo II, Santa Cruz e Lauro Sodré) no município de Coari.

Tabela 1 - Tabela com a localização dos sítios estudados

\begin{tabular}{|l|l|l|l|}
\hline Nome do Sítio & $\begin{array}{l}\text { Coordenada UTM } \\
\text { (Zona 20M - Datum WGS84) }\end{array}$ & Município & Contexto \\
\hline Hatahara & N 9637622 - E 810686 & Iranduba & Multicomponencial - Com TPI \\
\hline Laguinho & N $9636486-$ E 819174 & Iranduba & Multicomponencial - Com TPI \\
\hline Lauro Sodré & N $9573607-$ E 545501 & Coarí & Unicomponencial - Com TPI \\
\hline
\end{tabular}




\begin{tabular}{|l|l|l|l|}
\hline Santa Cruz & N 9571247 - E 506441 & Coarí & Unicomponencial - Com TPI \\
\hline São Paulo II & N 9562182 - E 485124 & Coarí & Unicomponencial - Com TPI \\
\hline Nova Esperança & N 9524571 - E 404670 & Coarí & Multicomponencial - Com TPI \\
\hline Santa Fé & N 9529979 - E 419322 & Coarí & Unicomponencial - Sem TPI \\
\hline
\end{tabular}

5 A área de confluência foi estudada sistematicamente de 1995 a 2010 no Projeto Amazônia Central. As pesquisas apresentaram evidências que questionaram o chamado "modelo cardíaco" de Lathrap, que propunha ter sido a Amazônia central o núcleo mais antigo de produção de cerâmicas da Tradição Polícroma, bem como a possível relação diacrônica entre cerâmicas das fases Manacapuru e Guarita nessa região (Neves, 2003, 2008a; Heckenberger; Neves; Petersen, 1998; Machado, 2005). Os estudos confirmaram também a existência de grandes assentamentos com presença da Terra Preta de Índio (TPI) e estruturas monticulares artificiais associadas à Tradição Borda Incisa (TBI). Os sítios arqueológicos da área de confluência têm depósitos espessos e multicomponenciais, chegando, em alguns casos, a quase $300 \mathrm{~cm}$ de profundidade. Os componentes superiores das ocupações desses sítios têm cerâmicas associadas à fase Guarita, foco deste trabalho. Tais ocupações marcam uma ruptura nas formas de assentamento e na técnica de produção de cerâmica, se comparadas com as ocupações anteriores (Machado, 2005; Moraes, 2006; Neves, 2003, 2008a, 2013; Lima; Neves; Petersen, 2006; Lima, 2008; Castro, 2009; Rebellato, 2007; Trindade, 2009). Há também evidências de que a transição para as ocupações Guarita, ao redor do ano 1000 d.C., foi marcada por conflitos, o que é atestado por um número de estruturas defensivas, como paliçadas e valas, construídas nessa época (Moraes \& Neves, 2012; Neves, 2008b).

Figura 1 - Sítios arqueológicos pesquisados por Tamanaha (2012) no baixo rio Solimões.

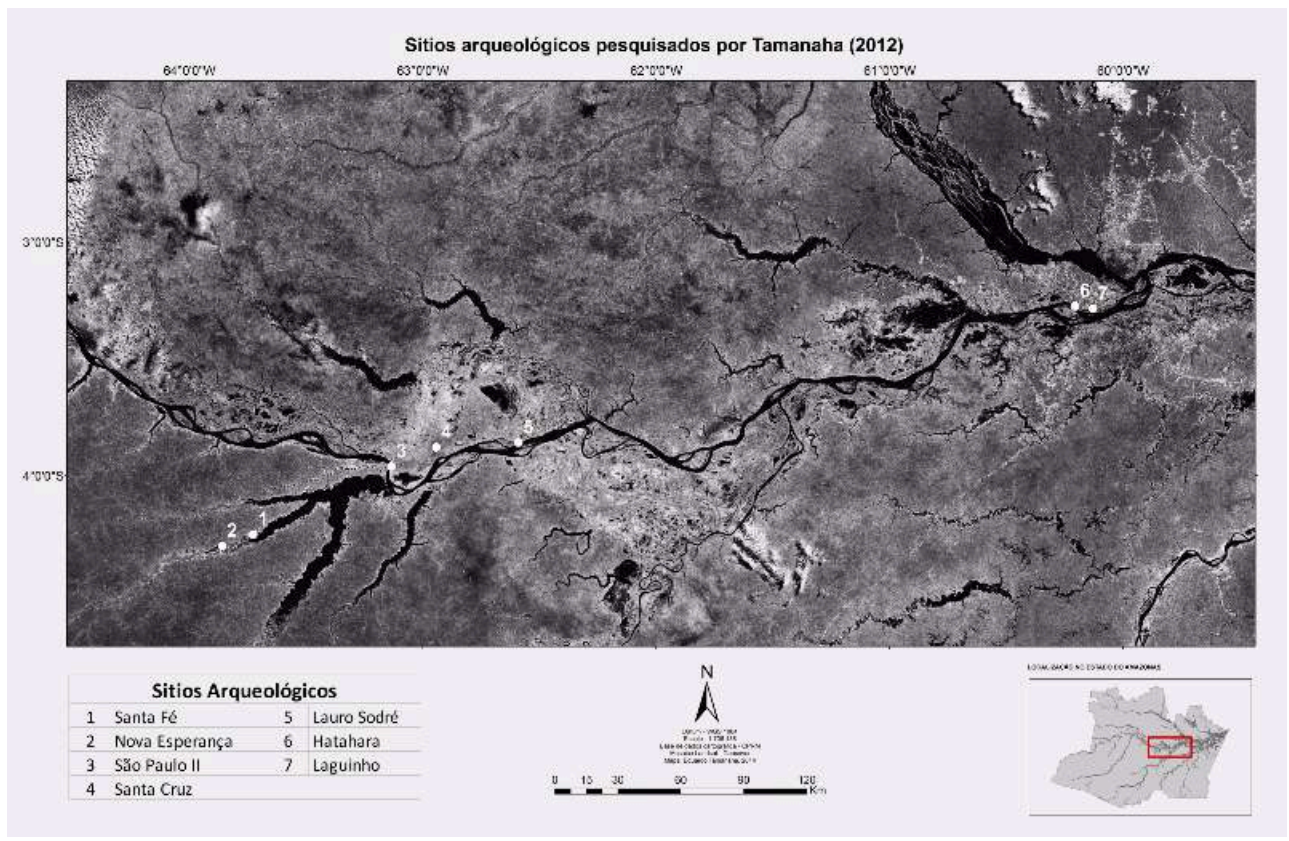

6 Já no município de Coari, os trabalhos de Peter Paul Hilbert (1968) e Wanda Hanke (1959) contribuíram na identificação, caracterização e datação de sítios arqueológicos, 
sendo que muitos foram associados à cerâmica Guarita. Outra quantidade expressiva de dados foi produzida no âmbito de dois projetos de arqueologia preventiva entre $1998 \mathrm{e}$ 2009: o poliduto Urucu-Coari (Caldarelli, 1998) e o Gasoduto Coari-Manaus (Neves, 2010). Ao todo, foram identificados 73 sítios nesses dois projetos, em um trecho que corresponde aproximadamente a $700 \mathrm{~km}$, sendo que uma boa porcentagem desses sítios apresentou somente material polícromo. Como resultado dessas obras, surgiu o projeto multidisciplinar PIATAM (Inteligência Socioambiental Estratégica da Indústria do Petróleo na Amazônia), como forma de monitoração dos impactos causados pelo transporte de gás e óleo pelo Rio Solimões e seus afluentes. Esse projeto identificou 86 sítios arqueológicos em todo o trecho (Lima \& Tamanaha, 2007, 2008).

Figura 2 - Sítios arqueológicos identificados durante o Projeto Piatam (Lima e Tamanaha 2007, 2008) e Gasoduto Coari-Manaus (Neves, 2010).

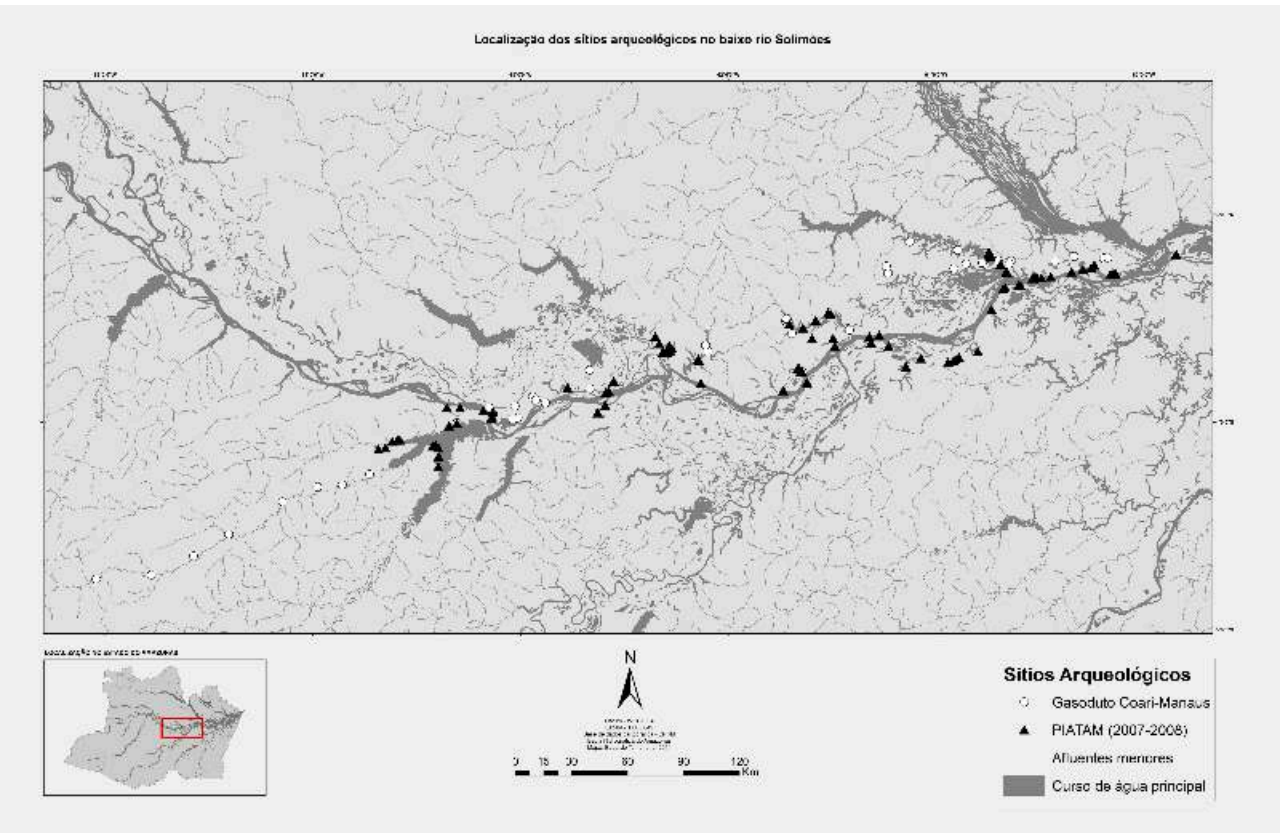

Os dados aqui apresentados foram coletados no âmbito de pesquisas em três dos projetos acima elencados: Projeto Amazônia Central (sítios Hatahara e Laguinho), PIATAM (sítio Lauro Sodré) e Levantamento Arqueológico do Gasoduto Coari-Manaus (sítios Santa Fé, Santa Cruz, Nova Esperança e São Paulo II).

\section{Conceitos e metodologia}

$\mathrm{Na}$ arqueologia dos grupos cerâmicos da Amazônia, em ocupações associadas às Terras Pretas Antrópicas, é interessante notar a manifestação local de uma história de longo prazo, sem rupturas marcantes nas formas de ocupação e na produção cerâmica. Esse período que se iniciou ao redor de 1000 a.C. e se estendeu a quase 1000 d.C. é representado no registro arqueológico pela Tradição Pocó-Açutuba e pelas fases Manacapuru e Paredão (TBI) na Amazônia Central (Neves et al., no prelo). Por outro lado, a partir de 750 d.C., surgiram as primeiras evidências de cerâmicas Guarita em vários afluentes do Solimões-Amazonas, causando uma ruptura cultural no modo de fazer cerâmica. Sua ocorrência abrange tanto áreas previamente ocupadas, como a 
Amazônia Central, quanto locais sem vestígios de ocupações anteriores, como a região de Coari (Tamanaha, 2012).

9 As diferenças entre as cerâmicas Guarita e as cerâmicas anteriores são visíveis, pois a intensidade da aplicação de pinturas policrômicas, aliada aos motivos plásticos acanalados, com ou sem a aplicação de uma flange mesial, cria um aspecto visual que as distingue de suas antecessoras. No caso das fases da TBI, é notória a construção de flanges labiais como suporte para a decoração plástica modelada e o uso da incisão como elemento decorativo primordial (Lima \& Neves, 2011). Esses aspectos da cerâmica Guarita contextualizados na estratigrafia dos sítios multicomponenciais permitiram uma identificação mais precisa dos conjuntos de fragmentos que seriam analisados.

objetivando analisar esse fenômeno polícromo inserido em um contexto regional (Baixo Rio Solimões) e em um recorte temporal (séculos VIII d.C. a XVI d.C.), foram postuladas duas noções teóricas. Relacionadas ao conceito de tecnologia, essas noções favoreceram as análises e a interpretação das informações obtidas: os hábitos motores e a questão de ensino e aprendizagem, ambos resultando nas tecnologias aplicadas na confecção das vasilhas.

11 Conforme observado por Schiffer e Skibo (1992), tecnologias vão além de ser ferramentas para manipular o meio ambiente, pois envolvem comportamentos e conhecimentos construídos reproduzidos e compartilhados no espaço e no tempo. Esse conjunto de saberes fornece ao artesão um "leque de escolhas" que podem ser aplicadas desde a aquisição de matérias-primas até a criação e uso dos vasos cerâmicos.

12 A não utilização de determinadas tecnologias (por exemplo, tipos de antiplásticos) não quer dizer necessariamente que houve falha na transmissão do conhecimento técnico, mas demonstra escolhas do artesão por várias razões, sejam elas simbólicas, sociais ou ambientais (Lemmonier, 1992; Schiffer \& Skibo, 1997; Silva, 2007). Arnold (1985) chama a atenção para as barreiras à inclusão de novas tecnologias, que estariam relacionadas a comportamentos já estabelecidos e incompatíveis com elas. Do mesmo modo, o uso e a função do artefato podem influenciar a escolha de determinados atributos (Rice, 1987; Sheppard, 1956). Como demonstrado por Gosselain (1998:87) em seu estudo no sul de Camarões, várias técnicas de produção (preparo da argila, tipo de antiplásticos, atmosfera de queima e tratamento de superfície antes e pós-queima) podem atingir o mesmo objetivo funcional. $\mathrm{O}$ autor averiguou, entre vários grupos, que uma mesma morfologia de vaso com tamanho e formas iguais foi produzida com técnicas diferentes.

13 Em suma, as técnicas podem variar no espaço e no tempo sem alterar a forma e função de um determinado tipo de vasilhame. Isso está correlacionado com o processo de ensino e aprendizagem, em que o comportamento técnico ou os hábitos motores (Arnold, 1985) resultam de disposições adquiridas socialmente sem a incorrência de determinismos ambientais, técnicos ou funcionais (Gosselain, 1998). Segundo Gosselain, o momento de criar a forma de um vaso é o estágio da produção em que gestos e posturas utilizados para dar o molde são transmitidos de maneira não verbal. Isso porque a etapa de moldar a argila demanda técnicas mais precisas, pois uma parede pode se tornar muito fina ou grossa conforme o alisamento ou algumas partes podem se tornar irregulares de acordo com a pressão exercida pelas mãos do ceramista, entre outras dificuldades. Portanto, os hábitos motores são passados de geração a geração, permitindo uma estabilidade estrutural (física) na composição do vaso, enquanto outros aspectos tecnológicos sofrem manutenção de acordo com fatores sociais ou simbólicos. Gosselain fala também do modo de aprendizagem, pois existe a questão da comunicação 
e distância entre professor e aluno. Nesse caso, populações que são linguisticamente afiliadas ou que compartilham uma história e/ou política tendem a possuir morfologias semelhantes ou técnicas que podem diferir, em algum aspecto, das adotadas por grupos vizinhos.

Os métodos de análise utilizados nos sítios aqui estudados seguiram, com algumas adaptações, o protocolo utilizado desde 1995 pelo Projeto Amazônia Central (Neves, 2000, 2003, 2008b, 2010), que tem permitido identificar as escolhas feitas pelas ceramistas durante o processo de manufatura do vaso. A triagem e a curadoria das coleções cerâmicas obedeceram aos seguintes procedimentos: lavagem e secagem do material; e, posteriormente, triagem dos fragmentos cerâmicos considerando as diversas partes do vaso - bordas decoradas, bordas sem decoração, bases decoradas, bases sem decoração, paredes decoradas e paredes sem decoração. Tais categorias não são excludentes, podendo, por exemplo, uma borda possuir também uma parede e uma base, o que implica uma hierarquia de classificação segundo a ordem acima mencionada. Essa definição é baseada no grau de informação que pode ser adquirido por meio de um fragmento como parte de um vasilhame.

Neste trabalho, foram separadas somente as bordas decoradas e sem decoração e as paredes com aspectos diagnósticos que remetem à morfologia de um vaso, tais como flanges mesiais ou carenas. $O$ objetivo principal dessa etapa foi a formação de conjuntos cerâmicos com base na morfologia do vaso e a sua caracterização tecnológica por meio dos atributos. A ficha de análise utilizada abordou tanto aspectos tecnológicos quanto decorativos, pois esses elementos podem estar relacionados na composição do vaso. Ao todo, foram analisadas 25 categorias que abrangem diversas variáveis, lembrando que em alguns casos - como no acabamento do lábio, antiplástico, natureza da peça ou tipo e local de decoração - existe a possibilidade de haver mais de uma característica na cerâmica (por exemplo, acabamento do lábio com engobo e serrilhado; decoração pintada interna com engobo interno ou borda com flange mesial e flange labial). Essa metodologia de análise foi elaborada com a participação de diversos pesquisadores do Projeto Amazônia Central (Machado, 2005; Lima, 2008:172; Tamanaha, 2012:74; Lima, 2014:89) e, apesar de ser específica para a cerâmica dessa região, tem correspondido às nossas necessidades e problemáticas (Machado, 2005; Lima, 2008; Moraes, 2006; Trindade, 2009).

\section{Análise cerâmica e conjuntos morfológicos}

Durante a pesquisa, foram explorados os atributos tecnológicos e morfológicos da cerâmica e as diferentes maneiras de interpelação desses atributos. Os dados obtidos resultaram na formação de 14 conjuntos definidos a partir da morfologia e projeção das bordas analisadas, com base em atributos como inclinação e forma da borda, forma e contorno do vaso, tipo e local de decoração. Cada uma dessas morfologias possui alguma variação, o que não implica a alteração da composição do vaso. A tabela abaixo apresenta a quantidade de fragmentos pertencentes a cada um dos conjuntos, separados por sítio arqueológico. Vale ressaltar que a ausência de uma forma não está necessariamente ligada à sua ausência no sítio, podendo ser apenas uma questão amostral. 
Tabela 2 - Índice quantitativo dos conjuntos por sítio arqueológico

\begin{tabular}{|c|c|c|c|c|c|c|c|}
\hline & Hatahara & Laguinho & Sta Fé & N. Esperança & São Paulo II & Sta Cruz & Lauro Sodré \\
\hline Conj. 1 & 0 & 0 & 0 & 1 & 17 & 24 & 1 \\
\hline Conj. 2 & 0 & 0 & 0 & 0 & 2 & 0 & 2 \\
\hline Conj. 3 & 0 & 0 & 0 & 0 & 2 & 0 & 22 \\
\hline Conj. 4 & 6 & 2 & 2 & 3 & 31 & 36 & 5 \\
\hline Conj. 5 & 0 & 0 & 0 & 0 & 3 & 22 & 1 \\
\hline Conj. 6 & 0 & 0 & 0 & 0 & 0 & 0 & 6 \\
\hline Conj. 7A & 13 & 7 & 3 & 8 & 43 & 24 & 6 \\
\hline Conj. 7B & 0 & 0 & 0 & 0 & 0 & 0 & 24 \\
\hline Conj. 8 & 2 & 9 & 3 & 6 & 85 & 29 & 0 \\
\hline Conj. 9 & 4 & 4 & 3 & 0 & 39 & 14 & 5 \\
\hline Conj. 10 & 0 & 0 & 0 & 0 & 1 & 0 & 41 \\
\hline Conj. 11 & 0 & 0 & 0 & 0 & 0 & 0 & 5 \\
\hline Conj. 12 & 0 & 0 & 0 & 0 & 3 & 0 & 2 \\
\hline Conj. 13 & 0 & 0 & 0 & 0 & 0 & 0 & 6 \\
\hline
\end{tabular}


Figura 3 - Representações dos conjuntos morfológicos obtidos para a fase Guarita no baixo rio Solimões.

\section{Conjuntos morfológicos identificados durante a análise cerâmica}
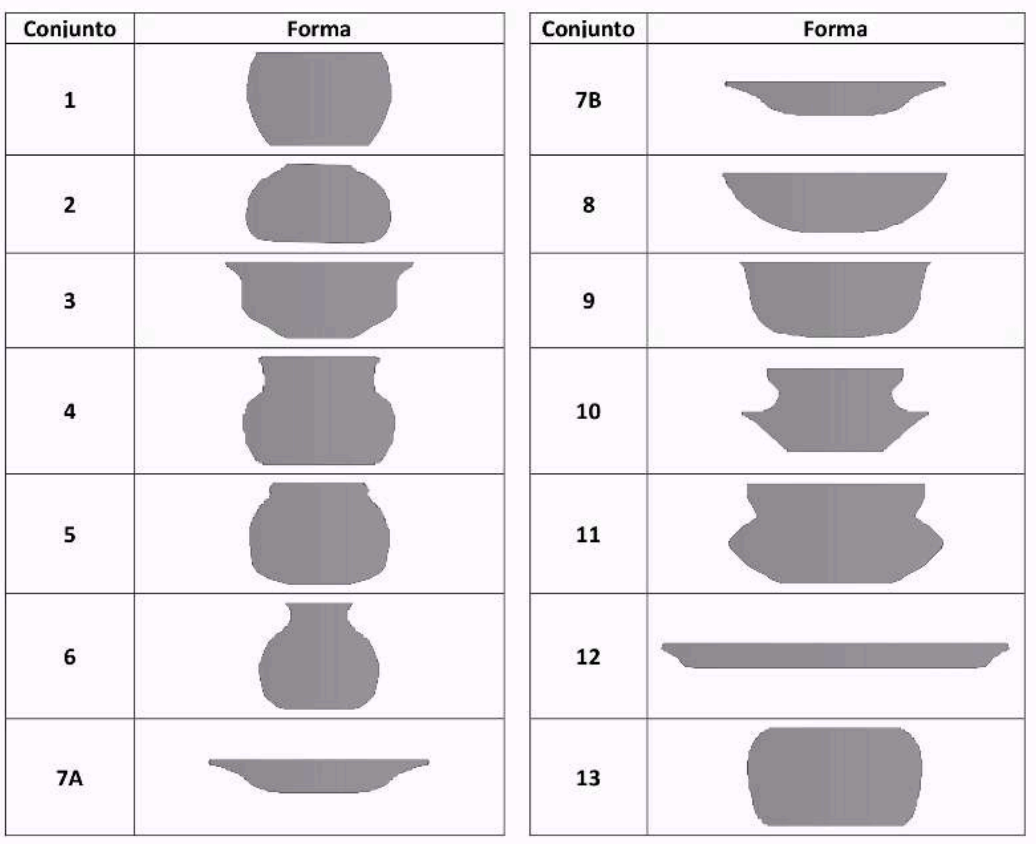

Exemplo dessa questão amostral é o sítio Lauro Sodré, que tem alta parcela de vasilhas inteiras. Esse é o único sítio que possui 13 dos 14 conjuntos propostos. Os sítios São Paulo II e Santa Cruz são densos se comparados com os demais, e sua amostragem de fragmentos de bordas possibilitou a identificação de vários conjuntos semelhantes em uma escala intersítio. Os demais sítios possuem uma baixa densidade de material associado à TPA, necessitando de uma maior amostragem para refinar os dados quanto à variabilidade morfológica da fase Guarita. Apresentaremos a seguir três conjuntos (4, 7 e 10) com maior representatividade na amostragem, seja pela sua presença em vários sítios, seja por características específicas da cerâmica. ${ }^{1}$

O conjunto 4 é formado por vasilhas esféricas, contorno composto e forma restritiva no pescoço, formando um gargalo. ${ }^{2} \mathrm{O}$ diâmetro da boca varia entre 14 e $26 \mathrm{~cm}$, e a espessura do fragmento, entre 9 e $15 \mathrm{~mm}$. $O$ conjunto apresenta bordas com inclinações diretas e extrovertidas e sua forma é relacionada, majoritariamente em todos os sítios, com a aplicação de rolete na face externa, reforçando a região do lábio. As decorações variam conforme o sítio, com preponderância da decoração plástica externa. Quanto aos antiplásticos, a maior ocorrência é de cauixi, com exceção do sítio Santa Cruz, que apresenta caraipé. Em sua composição morfológica, duas características estão sempre presentes: o gargalo possui campo decorativo pintado e o seu bojo esférico tem decorações plásticas acanaladas, acompanhadas ou não de engobo branco recobrindo a superfície externa.

O conjunto 7, presente em todos os sítios estudados, é formado por vasilhas elipsoidais rasas com contorno simples e forma irrestritiva, muito semelhante a um prato. 0 diâmetro varia entre 15 e $50 \mathrm{~cm}$, e a espessura, entre 11 e $21 \mathrm{~mm}$. As inclinações das bordas variam entre extrovertida e direta, com maior recorrência desta última. A forma 
da borda varia, principalmente, entre o roletado externo e o reto. Quanto aos aspectos decorativos, há uma grande variação de sítio para sítio, com preponderância da presença de engobo em ambas as faces. A decoração plástica é menos representativa nesse conjunto e, quando ocorre, aparece na face externa em forma de uma faixa horizontal. Os antiplásticos mais recorrentes são o cauixi, o caraipé e o caco moído. É um dos conjuntos diagnósticos dessa fase cerâmica, e a combinação de suas características não deixa dúvida quanto a sua filiação cultural. São vasilhas bem abertas, com pouca profundidade, e possuem uma cobertura de engobo branco principalmente a parte superior da face interna -, acompanhada de diversos motivos pintados em vermelho ou preto.

O conjunto 10 é formado por vasilhas com contorno complexo, forma restritiva ou direta, presença de flange mesial no meio ou na parte superior do bojo e boca quadrangular (região de Coari) ou circular (Coari e área de confluência). ${ }^{3}$ As vértices ou diâmetros variam entre 12 e $22 \mathrm{~cm}$, e a espessura do fragmento, entre 9 e $14 \mathrm{~mm}$. Essa morfologia é diagnóstica da fase Guarita, havendo registros de sua ocorrência em outras áreas da Amazônia (Simões et al., 1987; Miller et al., 1992; Moraes, 2013; Trindade, 2009) e estudos específicos em andamento sobre esse conjunto (Oliveira, 2014). A inclinação da borda pode ser direta, extrovertida e introvertida, com maior recorrência da primeira. Quanto à forma, houve maior representação do tipo biselado e expandido. Todos os fragmentos e vasilhas inteiras apresentaram decoração plástica externa e, em alguns casos, houve resquício de pintura e/ou engobo. Entre os antiplásticos, tiveram preponderância o cauixi e o caraipé, conforme o sítio. Esses vasos com flange mesial representam a junção de dois "corpos" diferenciados, por meio da inflexão, da carena ou da própria flange mesial. É muito semelhante ao que La Salvia e Brochado (1989:116) descreveram para a cerâmica Guarani como "[...] empilhamento de zonas ou segmentos horizontais bem demarcados". Em linhas gerais, esses vasos possuem três segmentos, sendo a primeira divisão marcada por uma inflexão ou carena, que afunila levemente o seu bojo superior, e a flange mesial, que divide o médio bojo da base do vasilhame. Além dessa divisão estrutural física, cada segmento possui alguma decoração plástica (por exemplo, faixas de acanalado pintado em torno do vaso) delimitando o seu campo decorativo e sua extensão possui pequenas variações. 


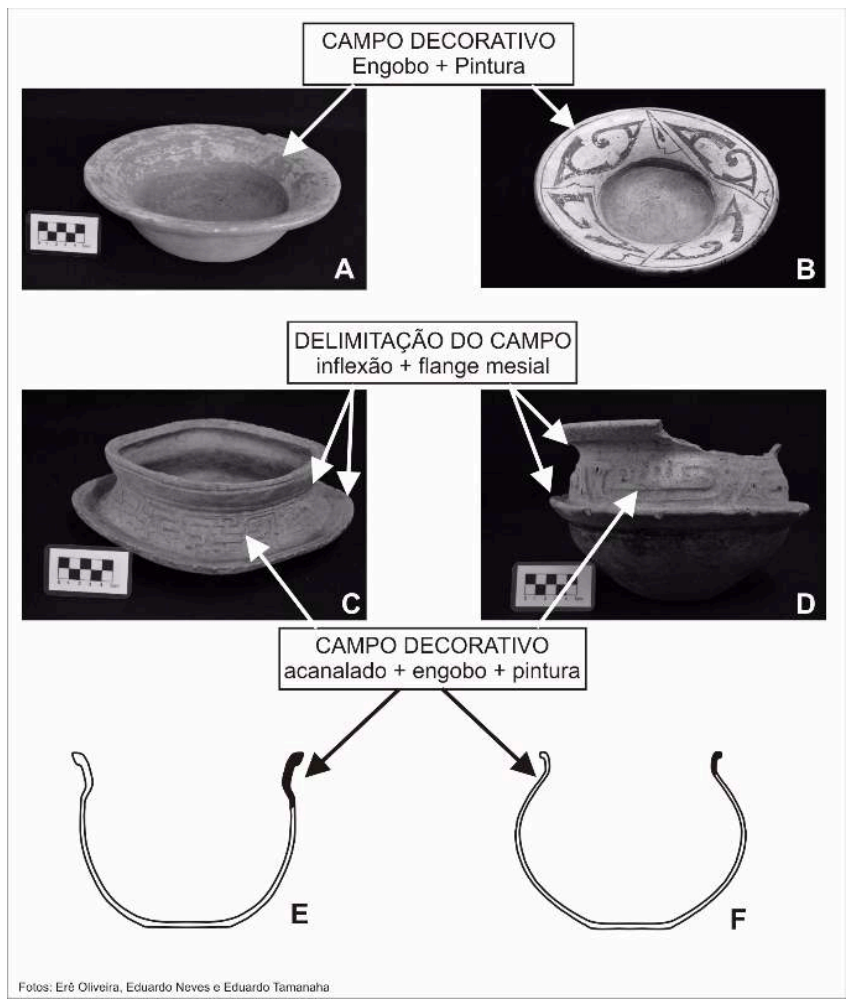

PRANCHA COM Fotos do CONJUNTO 7A (FIg. 4A E FIg. 4B), CONJUNTO 10 (FIg. 4C E 4D) E A PROJEÇÃo DE VASOS DO CONJUNTO 4 (FIg. 4E E FIg. 4F). 4A - PRATO dO SITIO LAURO SODRÉ; 4B - PRATO COLETADO NO MUNICÍPIO DE TONANTINS, ALTO SOLIMÕES; 4C - VASO COM FLANgE DO SÍTIO LAURO SODRÉ; 4D - VASO COM FLANgE COLETADO NO BAIXO RIO NEgRO; 4E E 4F - PROJEÇÃO dOS VASOS PIRIFORMES dO SÍTIO SÃO PAULO II.

21 De modo geral, em uma escala intrassítio, independente do conjunto representado, averiguamos que há várias opções tecnológicas sendo utilizadas, mas sempre com um predomínio de uma opção. No entanto, quando ampliamos o foco para uma comparação regional intersítio, concluímos que não há uma padronização tecnológica em relação ao preparo da pasta, contrapondo a morfologia dos vasos e as técnicas decorativas.

Já era esperado que a policromia fosse um elemento permanente nessa cerâmica (não é por acaso que a fase Guarita está inclusa na Tradição Polícroma da Amazônia), com a presença de engobo branco ou vermelho associado a motivos pintados em tons avermelhados e pretos. $\mathrm{O}$ uso da decoração plástica acanalada também é recorrente e, em muitos casos, é o fator que acompanha os traços e a espessura da pintura (pintura dentro do motivo acanalado). Essa técnica plástica se diferencia das cerâmicas da Tradição Borda Incisa/Barrancoide, em que o uso da incisão é mais recorrente. Os lábios das bordas, de modo geral, possuem espessuras mais grossas que o resto do vaso, seja na forma "expandida", seja na presença do rolete de reforço externo. As flanges mesiais, que definem um conjunto específico de vasos, estão localizadas no meio do bojo ou um pouco acima dele e apresentam diferentes comprimentos.

23 A pesquisa mostrou que há uma grande variabilidade formal na cerâmica da fase Guarita e que nem todas as formas estão presentes nos sítios estudados. Não está claro ainda por que algumas formas aparecem somente em alguns sítios, o que pode ser uma questão de função dos assentamentos escavados (Beletti, 2013). Conforme postulamos na conceituação teórica, acreditamos que essas variações tecnológicas e a permanência 
da forma nos vasilhames, tanto numa escala espacial como numa temporal, estão intrinsecamente relacionadas ao processo de escolhas do artesão e à relação de ensino e aprendizagem (Silva, 2000; Schiffer \& Skibo, 1997).

\section{Cronologia da TPA}

24 As ocupações relacionadas à fase Guarita na Amazônia Central iniciaram-se em torno do ano 1000 d.C., rompendo em vários aspectos com as ocupações anteriores, associadas à Tradição Borda Incisa. As datas adquiridas pelo Projeto Amazônia Central e pelo Gasoduto Coari-Manaus mostram que esses grupos polícromos surgiram a partir de 1280 d.C. na margem do Baixo Rio Solimões (sítio Laguinho) e de 900 d.C. na margem do Baixo Rio Negro (sítio Açutuba), prolongando-se até o período do contato europeu (Castro, 2009; Lima, 2008). No Baixo Rio Madeira, há evidências de produção e utilização dessas cerâmicas polícromas até o século XVII (Moraes, 2013:241).

Tabela 3 - Datações radiocarbônicas adquiridas para contextos associados a Tradição Polícroma da Amazônia no baixo rio Solimões.

\begin{tabular}{|l|l|l|l|l|}
\hline Sítio & Código & Amostra & Data Convencional & $\begin{array}{l}\text { Data Calibrada } \\
(2 \text { Sigma })\end{array}$ \\
\hline Açutuba & Beta 90009 & Cerâmica & $980 \pm 60$ AP & 990 DC - 1160 DC \\
\hline Açutuba & Beta 97529 & Cerâmica & $790 \pm 40$ AP & 1210 DC - 1270 DC \\
\hline Boa Esperança & Beta 321195 & Cerâmica & $1220 \pm 30$ AP & 760 DC - 890 DC \\
\hline Coarí I & - & Cerâmica & $800 \pm 57$ AP & 1093 DC - 1207 DC \\
\hline Coarí II & - & Cerâmica & $1187 \pm 48$ AP & 715 DC - 811 DC \\
\hline Hatahara & Beta 143582 & Carvão & $350 \pm 40$ AP & 1470 DC - 1640 DC \\
\hline Lago do Limão & OxA 15504 & Cerâmica & $625 \pm 26$ AP & 1290 DC - 1400 DC \\
\hline Laguinho & Beta 258148 & Cerâmica & $630 \pm 4$ AP & 1280 DC - 1410 DC \\
\hline Monte Sinai & Beta 242444 & Carvão & $670 \pm 40$ AP & 1280 DC - 1310 DC \\
\hline Monte Sinai & Beta 242445 & Carvão & $670 \pm 40$ AP & 1280 DC - 1310 DC \\
\hline Nova Esperança & Beta 242447 & Carvão & $850 \pm 40$ AP & 1050 DC - 1090 DC \\
\hline Santa Fé & Beta 242454 & Carvão & $1140 \pm 40$ AP & 780 DC - 990 DC \\
\hline
\end{tabular}

25 Ao longo do Rio Solimões, até o município de Coari, as datas são relativamente próximas às obtidas na Amazônia Central, com uma ocupação em torno de 1150 d.C. (Hilbert, 1968) no município de Coari e 1280 d.C. no sítio Monte Sinai, localizado em um lago no município de Codajás, a jusante de Coari e na margem esquerda do Rio Solimões (Neves, 2010). No entanto, as datas mais antigas para essas ocupações foram obtidas nos 
afluentes do Rio Solimões, iniciando em 763 d.C. (Hanke, 1959) e 770 d.C. (Neves, 2010) no município de Coari; 780 d.C. (Costa, 2012) no município de Tefé; e uma data mais tardia no sítio Nova Esperança, em torno de 1160 d.C.

Figura 5 - Localização e cronologia das fases arqueológicas vinculadas à Tradição Polícroma da Amazônia

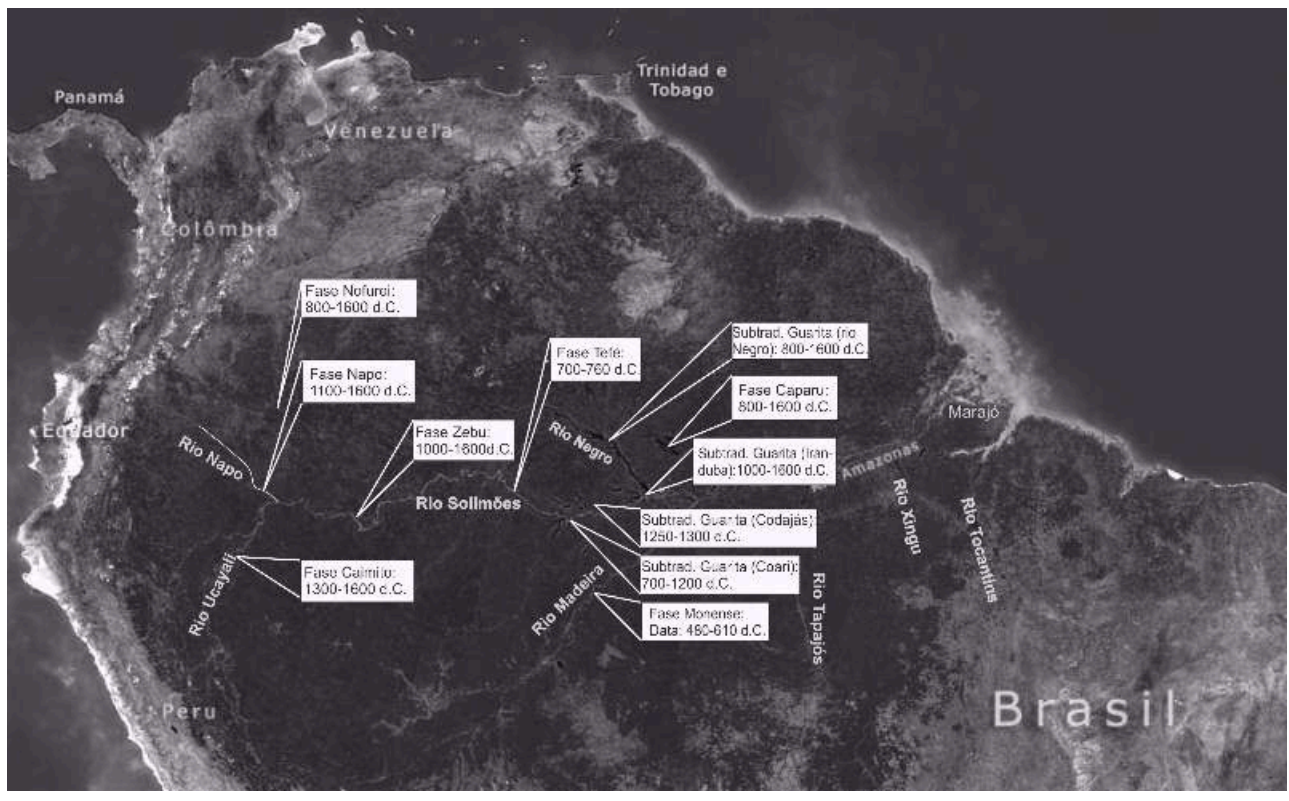

Extraído e adaptado de Almeida, 2013: 320.

Em suma, as datas mais antigas relacionadas às ocupações da TPA na bacia do Solimões estão localizadas nos afluentes desse rio. A presença da TPA ao longo da sua calha principal e do Baixo Rio Negro surge em torno de 1000 d.C., não abandonando necessariamente os seus afluentes, como é o caso dos sítios Nova Esperança e Monte Sinai. As datas obtidas até o momento indicam uma ocupação mais antiga ao norte e ao sul do Rio Solimões-Amazonas. Isso quer dizer que, embora a expansão da TPA pareça ter ocorrido no sentido leste-oeste em uma escala continental (situando temporalmente a fase Marajoara no século $\mathrm{V}$ a leste e a fase Napo no século XII a oeste), em uma escala regional, o processo não foi linear. Isso nos auxilia a entender melhor o processo de expansão desses grupos, além de refutar argumentações puramente adaptativistas e a ideia de pressão demográfica na várzea, conforme proposto por Lathrap, como motor dessa expansão.

Obviamente, as ocupações relacionadas à TPA nas margens do Rio Solimões podem ser muito mais antigas do que as identificadas até o momento, uma vez que ainda há uma grande área para ser amostrada. Além disso, existe a possibilidade de nunca encontrarmos essas ocupações mais antigas em determinados trechos desse rio, devido à erosão lateral acelerada ou ao fenômeno das "terras caídas" que ocorrem com frequência nas planícies de alagação. Sítios localizados nos afluentes e lagos de água preta podem conter um compartimento hidrográfico mais estável e, portanto, preservar um contexto arqueológico mais antigo. 


\section{Conclusões}

28 Na virada do primeiro milênio, grande parte das margens do Rio Solimões e parte do Baixo Rio Negro estavam ocupadas por populações que produziam cerâmicas associadas à fase Guarita da Tradição Polícroma da Amazônia. A TPA vem sendo estudada desde a primeira metade do século $\mathrm{XX}$, e um dos principais focos do debate diz respeito à sua origem e aos processos que levaram a sua expansão. Esses temas ainda estão longe de ser esclarecidos, mas os resultados de nossas análises trazem uma pequena contribuição ao debate. Eles mostram que, ao redor de 1000 d.C., a fase Guarita era caracterizada por uma indústria estável quanto aos tipos de formas, mas tinha grande variabilidade quanto às técnicas para fazer essas formas. Tal padronização formal teve também uma expressão diacrônica, conforme atestado pelos dados obtidos no sítio Santa Fé, ocupado no século VIII d.C. Os aspectos decorativos, aliados ao tratamento de superfície, também são características que permanecem na cerâmica, como o engobo branco ou vermelho associado a pinturas com tons avermelhado ou preto e decorações plásticas acanaladas. Outros atributos, como o uso de flange mesial e o reforço labial externo, permanecem no espaço e no tempo, isto é, são elementos diagnósticos da fase Guarita. Essa estabilidade nas formas dos artefatos cerâmicos está associada a processos de ensino e aprendizagem, incorporados nos hábitos motores do aprendiz.

Levando em consideração os aspectos da estabilidade da forma e variação tecnológica das cerâmicas, as cronologias obtidas para esses sítios e a inserção dessas ocupações no espaço, é possível elaborar hipóteses sobre a expansão dessas populações ao longo do Rio Solimões. O histórico de expansão e a permanência de ocupações Guarita na área de confluência e no Médio Solimões podem ser divididos em três momentos: séculos VIII-X d.C., com as primeiras evidências de ocupação nos afluentes do Rio Solimões; séculos $\mathrm{XI}-\mathrm{XV}$ d.C., com o seu estabelecimento em vários locais do rio e o conflito com os antigos habitantes; e século XVI d.C., com a chegada dos portugueses e espanhóis, que descreveram a presença desses grupos. São três momentos com processos históricos diferenciados tanto no espaço como no tempo. Se não há ainda um panorama exato, o intuito deste trabalho é esboçar um contexto histórico do Baixo Rio Solimões nos séculos que antecederam o início da colonização europeia.

Nesse esboço, teríamos inicialmente ocupações associadas à TPA em afluentes, com assentamentos pequenos e ausência de terra preta - é o caso do sítio Santa Fé -, o que nos leva a pensar em uma ocupação de baixa permanência e pouca densidade demográfica. Nessa mesma época, final do século VIII d.C., é notável uma ocupação associada à cerâmica da Tradição Borda Incisa em uma área próxima, no sítio Nova Esperança, a $15 \mathrm{~km}$ em linha reta do sítio Santa Fé. Não há nenhum indicativo de como teria sido essa relação, mas, após aproximadamente 300 anos de abandono, o sítio Nova Esperança seria ocupado pelos grupos da TPA em torno de 1050 d.C. (Tamanaha, 2012; Lima, 2008).

31 Posteriormente, em torno do século XI d.C., grande parte do Rio Solimões passa a ser ocupado pelos grupos produtores de cerâmicas da TPA, que se estabeleceram tanto em áreas não ocupadas anteriormente (região de Coari) como em áreas previamente ocupadas (área de confluência dos rios Solimões e Negro). Esses ceramistas firmaram relações conflituosas com os grupos ali assentados, o que é atestado pela presença de valas defensivas datadas em torno desse período em sítios associados à fase Paredão (Moraes \& Neves, 2012). 

dos povos austronésios (Kirch, 2000). O complexo Lapita, que é o conjunto de vestígios arqueológicos deixado durante a expansão austronésia, cobre uma área com mais de $4.500 \mathrm{~km}$ no sentido leste-oeste e sua expansão ocorreu em um período de 200-300 anos. As novas áreas ocupadas não possuíam outras populações, como pode ter sido o caso da região de Coari, o que facilitou a mobilidade desses grupos pelas ilhas. Outro fator que deve ser levado em consideração no caso da fase Lapita é que essa rápida expansão implicou alto grau de natalidade, baixo índice de mortalidade e assentamentos de baixa densidade demográfica. Isso é justificado pela progenitura, ou seja, somente o primogênito teria direito ao governo daquela aldeia, forçando os demais filhos do chefe a buscar novas áreas para se fixarem (Bellwood, 1996b apud Kirch, 2000). Mas a razão mais explorada em outros casos é o advento da agricultura aliada à alta densidade demográfica como impulsionador da expansão de um determinado grupo cultural (Renfrew, 2000; Bellwood, 2001).

Passados 800 anos de ocupação da TPA, essa tradição cerâmica estaria dispersa por várias regiões da bacia amazônica, desde o piemonte andino até o litoral amazônico (Neves, 2008a). Cronistas descreveriam a diversidade de povos e línguas existentes nas margens dos rios Solimões-Amazonas. Por outro lado, a arqueologia mostraria que esses povos de línguas diferentes compartilhavam atributos cerâmicos. Esse cenário não é diferente de outras partes do mundo, onde existem mais línguas diferentes do que cultura material: Washo e Shoshone, na Grande Bacia do Nevada (Great Basin), os Pueblos do sudoeste estadunidense, a região da Califórnia, nos Estados Unidos, o norte da Nova Guiné e a região do Alto Xingu (Anthony, 2007). Já o oposto é um contexto raro, pois uma região homogênea linguisticamente dificilmente possuirá duas culturas distintas.

Em suma, no século XVI, temos uma vasta área na Amazônia ocupada por povos com características comuns na produção de artefatos cerâmicos. Apesar de não sabermos qual foi o motor que impulsionou essa expansão nem como se deram as relações entre os recém-chegados (TPA) e os outros grupos cerâmicos, sabemos que a dispersão da fase Guarita pelo Rio Solimões foi um processo multifacetado e plural. Seu entendimento 
demanda uma análise contextual pormenorizada, uma vez que cada região pode ter passado por um processo histórico diferenciado.

\section{BIBLIOGRAFIA}

ALMEIDA, Fernando Ozório de 2013 A Tradição Polícroma no alto rio Madeira Tese de Doutorado, Museu de Arqueologia e Etnologia da Universidade de São Paulo.

ANTHONY, David. 2007. The Horse, the Wheel and Language. New Jersey: Princeton University Press.

ARNOLD, Dean. 1985. Ceramic Theory and Cultural Process. Cambridge: Cambridge University Press.

BELLETTI, Jaqueline da Silva. 2013. Mapeamento arqueológico do Lago de Tefé, Médio Rio Solimões (Amazonas - Brasil). Memorial de Qualificação de Mestrado, Museu de Arqueologia e Etnologia da Universidade de São Paulo.

BELLWOOD, Peter. 2001. “Early Agriculturalist Population Diasporas? Farming, Languages and Genes”. Annual Review of Anthropology, 30:181-207.

BOOMERT, Arie. 2004. "Koriabo and the Polychrome Tradition: the Late-Prehistoric Era between the Orinoco and Amazon Mouths". In: Andre Delpuech \& Corinne Hofman. Late Ceramic Age Societies in the Eastern Caribbean. Oxford: Archaeopress.

BROCHADO, José Joaquim Justiniano Proença. 1989. “A expansão dos Tupis e da cerâmica da tradição policrômica da Amazônia”. Dédalo, 9:17-18.

CALDARELLI, Solange Bezerra. 1998. Relatório Final do Projeto de Levantamento e Resgate da Área de Influência Direta do Polioduto Urucu-Coari, AM. São Paulo: Scientia Consultoria.

CASTRO, Márcio Walter de Moura. 2009. A cronologia dos sítios Lago de Iranduba e Laguinho à luz das hipóteses de ocupação humana para a Amazônia Central. Dissertação de Mestrado, Museu de Arqueologia e Etnologia da Universidade de São Paulo.

COSTA, Bernardo Lacale Silva da. 2012. Levantamento arqueológico na Reserva de Desenvolvimento Sustentável (RDS) Amanã: estado do Amazonas. Dissertação de Mestrado, Museu de Arqueologia e Etnologia da Universidade de São Paulo.

DEBOER, Warren. 1981. "Buffer Zones in the Cultural Ecology of Aboriginal Amazonia: an Ethnohistorical Approach”. American Antiquity, 46(2):364-377.

GOSSELAIN, Olivier. 1998. “Social and Technical Identity in a Clay Crystal Ball”. In: Miriam Stark. Archaeology of Social Boundaries. Washington, DC: Smithsonian Institution Press. pp. 78-106.

HANKE, Wanda. 1959. “Archäologische Funde im oberen Amazonasgebiet”. Archiv für Völkerkunde, 14:31-66.

HECKENBERGER, Michael; NEVES, Eduardo Góes \& PETERSEN, James. 1998. "De onde surgem os modelos? A arqueologia da origem Tupi e Guarani”. Revista de Antropologia, 41(1):69-96. 
HILBERT, Peter Paul. 1968. Archäologische Untersuchungen Am Mittlern Amazonas. Berlim: Dietrich Reimer.

KIRCH, Patrick Von. 2000. On the Road of the Winds: an Archaeological History of the Pacific Islands before European Contact. Berkeley: University of California Press.

LA SALVIA, Fernando \& BROCHADO, José Joaquim Justiniano Proença. 1989. Cerâmica Guarani. Porto Alegre: Posenato Arte e Cultura.

LATHRAP, Donald. 1975. O Alto Amazonas. Lisboa: Verbo.

LEMMONIER, Pierre. 1992. Elements for an Anthropology of Technology. Michigan: Museum of Anthropological Research. University of Michigan.

LIMA, Helena Pinto. 2008. História das caretas: a tradição Borda Incisa da Amazônia Central. Tese de Doutorado, Museu de Arqueologia e Etnologia da Universidade de São Paulo.

LIMA, Helena Pinto \& NEVES, Eduardo Góes. 2011. "Cerâmicas da Tradição Borda Incisa/ Barrancóide na Amazônia Central”. Revista do Museu de Arqueologia e Etnologia, (21):205-230.

LIMA, Helena Pinto; NEVES, Eduardo Góes \& PETERSEN, James. 2006. “A fase Açutuba: um novo complexo cerâmico na Amazônia Central”. Arqueologia Suramericana, 2(1):26-52.

LIMA, Márjorie. 2014. O Rio Unini na arqueologia do Baixo Rio Negro, Amazonas. Dissertação de Mestrado, Museu de Arqueologia e Etnologia da Universidade de São Paulo.

LIMA, Márjorie \& TAMANAHA, Eduardo. 2007. Relatório final de atividades entregue ao Piatam. Manaus: PIATAM.

2008. Relatório parcial de atividades entregue ao PIATAM. Manaus: PIATAM.

MACHADO, Juliana Salles. 2005. Montículos artificiais na Amazônia Central: um estudo de caso do Sítio Hatahara. Dissertação de Mestrado, Museu de Arqueologia e Etnologia da Universidade de São Paulo.

MEGGERS, Betty Jane \& EVANS, Clifford. 1957. Archaeological Investigations at the Mouth of the Amazon. Washington: Smithsonian Institution Press. (Smithsonian Institution Bulletin, 167).

1961. “An Experimental Formulation of Horizon Styles in the Tropical Forest Area of South America”. In: Samuel Lothrop. Essays in Precolumbian Art and Archaeology. Cambridge: Harvard University Press. pp. 372-388.

1968. Archaeological Investigations on the Rio Napo, Eastern Ecuador. Washington: Smithsonian Institution Press.

MILLER, Eurico et al. 1992. Arqueologia nos empreendimentos hidroelétricos da Eletronorte: resultados preliminares. Brasília: Eletronorte.

MORAES, Claide de Paula. 2006. Levantamento arqueológico das áreas do entorno do Lago do Limão, Iranduba, Amazonas. Dissertação de Mestrado, Museu de Arqueologia e Etnologia da Universidade de São Paulo.

2013. Amazônia ano 1000: territorialidade e conflito no tempo das chefias regionais. Tese de Doutorado, Museu de Arqueologia e Etnologia da Universidade de São Paulo.

MORAES, Claide de Paula \& NEVES, Eduardo Góes. 2012. “O ano 1000 - adensamento populacional, interação e conflito na Amazônia Central”. Revista Amazônica, 4(1):122-148.

NEVES, Eduardo Góes. 2000. Levantamento arqueológico da área de confluência dos rios Negro e Solimões, estado do Amazonas. Relatório enviado à FAPESP. São Paulo: Museu de Arqueologia e Etnologia da Universidade de São Paulo. 
. 2003. Levantamento arqueológico da área de confluência dos rios Negro e Solimões, estado do Amazonas: continuidade das escavações, análise da composição química e montagem de um sistema de informações geográficas. Relatório enviado à FAPESP. São Paulo: Museu de Arqueologia e Etnologia da Universidade de São Paulo.

2008a. "Ecology, Ceramic Chronology and Distribution, Long-term History, and Political Change in the Amazonian Floodplain." In: Helaine Silverman \& Eilliam Isbell. Handbook of South American Archaeology. New York: Springer. pp. 359-379.

2008b. Cronologias regionais, hiatos e continuidades na história pré-colonial da Amazônia. Segundo relatório do projeto temático encaminhado à FAPESP. São Paulo: Museu de Arqueologia e Etnologia da Universidade de São Paulo.

. 2010. Serviços de estudos de prospecção, avaliação, salvamento e resgate de patrimônio arqueológico na implantação de faixa e abertura de Valas no Gasoduto Coari-Manaus e no GLPDuto Urucu-Coari. São Paulo: IPHAN.

. 2013. Sob os tempos do equinócio: oito mil anos de história na Amazônia Central (6500 a.C. - 1500 DC). Tese de Livre Docência, Museu de Arqueologia e Etnologia da Universidade de São Paulo.

NEVES, Eduardo Góes et al. No prelo. “A Tradição Pocó-Açutuba e os primeiros sinais visíveis de modificações na paisagens na calha do Amazonas".

OLIVEIRA, Erêndira. 2014. A variabilidade tecno-estilística da Tradição Polícroma da Amazônia: um estudo exploratório da iconografia Guarita. Memorial de qualificação de mestrado, Museu de Arqueologia e Etnologia da Universidade de São Paulo.

PAPAVERO, Nelson et al. 2002. O Novo Éden: a fauna da Amazônia brasileira nos relatos de viajantes e cronistas desde a descoberta do Rio Amazonas por Pizón [1500] até o Tratado de Santo Idelfonso [1777]. Belém: Museu Paraense Emílio Goeldi.

PORRO, Antônio. 1992. "História indígena do Alto e Médio Amazonas". In: Manuela Carneiro da Cunha. História dos índios no Brasil. São Paulo: Cia das Letras/SMC/FAPESP. pp. 175-196.

1996. O povo das águas. Petrópolis: Vozes.

REBELLATO, Liliam. 2007. Interpretando a variabilidade cerâmica e as assinaturas químicas e físicas do solo no sítio arqueológico Hatahara. Dissertação de Mestrado, Museu de Arqueologia e Etnologia da Universidade de São Paulo.

RENFREW, Colin. 2000. “At the Edge of Knowability: towards a Prehistory of Languages”. Cambridge Archaeological Journal, 10(1):7-34.

RICE, Prudence. 1987. Pottery Analysis: a Sourcebook. Chigaco: University of Chicago Press. RODRIGUES, José Barbosa. 1877. Arte cerâmica: antiguidades do Amazonas. Rio de Janeiro: [s.n.]. v. 2 .

SCHIFFER, Michael Brian \& SKIBO, James. 1992. "Theory and Experiment in the Study of Technical Change”. In: Michael Brian Schiffer. Technological Perspectives on Behavorial Change. Tucson: University of Arizona Press. pp. 40-76. . 1997. "The Explanation of Artifact Variability”. American Antiquity, 62(1):27-50. SHEPPARD, Anna. 1956. Ceramics for the Archaeologist. Washington D.C.: Carnegie Institution of Washington. (Publication 609). 
SILVA, Fabíola Andrea. 2000. As tecnologias e seus signifcados. Tese de doutorado, Faculdade de Filosofia e Ciência Humanas da Universidade de São Paulo.

. 2007. "O significado da variabilidade artefatual: a cerâmica dos Asurini do Xingu e a plumária dos Kayapó-Xikrin do Cateté”. Boletim do Museu Paraense Emílio Goeldi, 2(1):91-103.

SIMÕES, Mário et al. 1987. "Pesquisas arqueológicas no Médio Rio Negro (AM)". Revista de Arqueologia, 4(1):83-116.

TAMANAHA, Eduardo. 2012. Ocupação polícroma no Baixo e Médio Rio Solimões, estado do Amazonas. Dissertação de Mestrado, Museu de Arqueologia e Etnologia da Universidade de São Paulo.

TRINDADE, Thiago Berlanga. 2009. Os sítios Hatahara e São Paulo II e a expansão da Tradição Polícroma no Rio Solimões. Relatório final de iniciação científica, Museu de Arqueologia e Etnologia da Universidade de São Paulo.

\section{NOTAS}

1. Para maior detalhe dos conjuntos por sítio, consultar as pranchas de bordas no volume II de Tamanaha (2012).

2. Entendemos por contorno composto o vaso que possui somente uma inflexão ou carena.

3. Contorno complexo são vasos que possuem duas ou mais inflexões ou carena.

\section{RESUMOS}

Este artigo apresenta dados sobre o processo de ocupação de sítios com depósitos associados à cerâmica Guarita, da Tradição Polícroma da Amazônia, na região do Baixo Rio Solimões, no Amazonas. Essas ocupações estão relacionadas aos últimos grupos ceramistas que se estabeleceram na região desde o século VIII d.C. até o século XVI d.C. Por meio do exame do contexto arqueológico de sete sítios pré-coloniais e da análise tecnomorfológica da cerâmica, foi possível identificar semelhanças e diferenças entre duas áreas do Baixo Rio Solimões. A partir disso, propõe-se uma hipótese para a história de ocupação dos grupos ceramistas vinculados à Tradição Polícroma da Amazônia.

This article presents data about the process of site settlements associated to Guarita ceramics of Amazonian Polychrome Tradition, in the region of the Lower Solimoes River, Amazonas state. These occupations are associated with the last pottery making groups who settled in the region from the VIII century until the XVI century AD. Through the verification of the archaeological context associated with the pre-colonial vestiges and a techno-morphological analysis of pottery, it was possible to identify similarities and differences between two areas of the Lower Solimoes River. This article proposes a hypothesis for the history of the occupation of these ceramic groups tied to the Amazonian Polychrome Tradition. 
ÍNDICE

Keywords: Amazonia, archaeology, amazonian polychrome tradition, Solimoes River

Palavras-chave: arqueologia, Amazônia, tradição polícroma da Amazônia; Rio Solimões

\section{AUTORES}

\section{EDUARDO KAZUO TAMANAHA}

Instituto de Desenvolvimento Sustentável Mamiruá/MCT. Eduardo Kazuo Tamanaha é pesquisador do Instituto de Desenvolvimento Sustentável Mamirauá/MCT, em Tefé, Amazonas, e associado ao Laboratório de Arqueologia dos Trópicos do MAE/USP. É mestre e doutorando no Programa de Pós-Graduação em Arqueologia do MAE/USP. Contato: eduardo.tamanaha@usp.br

\section{EDUARDO GÓES NEVES}

MAE/USP. Eduardo Góes Neves é professor titular de Arqueologia Brasileira no MAE/USP e coordenador do Arqueotrop, na mesma instituição. Contato: edgneves@usp.br 